\title{
COMPETITION RULE OF THE MULTI-CRITERIA APPROACH: WHAT CONTRACTORS IN CHINA REALLY WANT?
}

\author{
Kunhui $\mathrm{YE}^{1^{*}}$, Dan ZENG ${ }^{2}$, Johnny WONG ${ }^{3}$ \\ ${ }^{1}$ School of Construction Management and Real Estate, Chongqing University, Chongqing, China \\ ${ }^{2}$ Research Centre for Construction Economics and Management, Chongqing University, Chongqing, China \\ ${ }^{3}$ School of the Built Environment, University of Technology, Sydney, Australia
}

Received 27 July 2017; accepted 22 February 2018

\begin{abstract}
Recent years have witnessed the diversifying means of competitive bidding, where the client plays a critical role in the determination of competition rule. It is widely recognized that the competition rule should be placed on a win-win basis to ensure that both the client and contractors are well considered with respect to their interests. Nevertheless, a vast majority of biddings fail to take account of what contractors really want. Using the methods of literature review and content analysis, 34 tender evaluation factors are proposed to compose the competition rule in China. Contractors' opinions on these factors are collected by virtue of questionnaire survey. Based on the Pareto law, it is found that the competition rule encompasses eleven key factors, and the composition varies slightly between public and private sectors. The Hotelling's $\mathrm{T}$ test is conducted on those key factors in common. The implication is that contractors can use indifferent factors (e.g., credit rating, construction plan, completeness of bid components, timely payment to workers) to improve competitiveness, while the client may utilize different factors to diversify the competition rule. This paper probably presents an earliest effort put to examine the acceptability of competition rule in the construction context.
\end{abstract}

Keywords: competition rule, competitive tendering, perception, project type, China.

\section{Introduction}

In the discipline of economics, competition refers to a rivalrous discovery process that takes place in parallel to organizational changes, innovation and evolution (Littlechild 2017). Effective competition enables production factors (e.g., capital, land, information, and human resources) to be allocated across a range of sectors in line with the tenet of human welfare maximization (Smith 1776), while inefficient competition may result in market failures. In the construction context, competition is enclosed mainly by contractors in struggle for construction work contracts (Ye et al. 2015). This kind of competition has been unfolded in a few fashions such as average price, the lowest price, and multi-criteria bidding (Wong et al. 2001). As pointed out by Christodoulou (2010), awarding construction contracts by virtue of the multi-criteria approach is an overriding style of effective competition in the construction industry. One of the reasons goes to its advantage of facilitating the client to screen out those contractors who are more competitive than counterparts in carrying out predefined construction assignments (Bottani, Rizzi 2008).
The efficiency of markets in allocating resources is contingent on competition rules that should be acceptable by a vast majority of both suppliers and demanders. However, the construction market has been a typical buyer market for a long time (Egemen, Mohamed 2005), where contractors as suppliers are given relatively feeble market powers. In case that the client offers an unreasonable price, contractors would take some countermeasures to secure a certain level of profitability in the subsequent construction process. For instance, they can choose to deliver construction projects with quality levels lower than stipulated. Furthermore, market disorders such as collusion, corruption, and unqualified contracts would be surfacing if contractors' competition against each other is irrational (Chotibhongs, Arditi 2012). In reverse, effective competition in the multi-criteria approach benefits contractors from fair business transaction and reaps profits as a consequence (Egemen, Mohamed 2005; Oo et al. 2008). Since the ultimate purpose of the multi-criteria approach is to determine most competitive contractors, the client has the

${ }^{*}$ Corresponding author. E-mail: Kunhui.YE@Gmail.com 
responsibility of devising competition rules that represent contractors' interests.

In the multi-criteria approach, tender evaluation criteria stay at the core of the competition rule (Liu et al. 2017). The client who runs the game as a referee reserves the right to amend tender evaluation criteria and requires tenderers to react to what they truly want as described in tender documents (Ng, Skitmore 1999; Fu et al. 2003). However, the key point is to secure the effectiveness and efficiency of tendering procedures, and to ascertain that any revision to tender evaluation criteria is acceptable to all parties involved. In appreciating a dearth of relevant research in this area, this study aims to examine the competition rule in the construction sector by collecting contractors' opinions on the multi-criteria approach. Due to the client's preference, project uniqueness, business environment, and locality of socio-economy (Newcombe 1990), the extent to which the multi-criteria approach is implemented varies from one project to another. In public projects, the tender evaluation has a number of boundaries and restrictions, including laws, regulations and procedures, but in private projects the tender evaluation process is more flexible, and more rational evaluation of criteria is usually adopted in the process (Kog, Yaman 2014). Contractors are not advised to use same competition strategies when they are competing for different types of construction projects simultaneously (Ye et al. 2014). Hence, competition rules for public and private construction projects are also examined in the study.

\section{Literature review}

\subsection{Tender evaluation criteria}

Tender evaluation criteria specify an overt way of business competition in the construction industry, where the client usually finds it arduous to give a precise description of construction projects at the very beginning. Business competition in the construction industry is more complex than those in the manufacturing and service industries in a couple of ways. First, the client's requirements on contractors largely include quality, schedule, cost, safety, and green construction, but the requirements are changeable over time. Second, some construction works are characterized with high technique, fragile surrounding environment and complexity of stakeholders. Contractors have to demonstrate that they have full capability to deal with any sort of challenges ahead. Third, what contractors compete for in construction projects are not bidding prices, but also an opportunity of being recognized in the quality of services delivery. Therefore, contractors might attempt to exhibit previous experiences, give rigorous analysis on construction assignments, and delineate outstanding management skills in tenders.

Of tender evaluation criteria is a multidimensional competition rule that contractors can find connected to organizational competitiveness like technical competence, management expertise, marketing and financial resources
(Liu et al. 2017). Watt et al. (2009) proposed nine parameters of tender evaluation criteria, namely organizational experience, project management expertise, tendered price, technical expertise, past project performance, reputation, method/solution, client-supplier relations, and workload/ capacity. According to Ho et al. (2010), the most popular criteria for the client to assess a contractor's competitiveness are quality, price/cost, manufacturing capability, service, management, technology, research and development, finance, and reputation. In effect, part of competitiveness parameters addressed in previous studies concur with each other, suggesting that notwithstanding diverse applications, the competition rules in the construction industry have some components in common.

Lu et al. (2008) asserted that a contractor's success factors vary distinctively with projects, implying that project type is an indicator for scrutinizing the client's efforts in devising competition rules. Whilst construction projects can be categorized in different ways (e.g. civil infrastructure, building and other physical facilities), the term project type mainly refer to public and private sector $(\mathrm{Ng}$, Skitmore 1999; Ye et al. 2014). In general, tender evaluation criteria for public and private projects are determined by the client in using them to mirror the uniqueness of construction projects and to ascertain the fluent operation of bidding in a dynamic circumstance characterized by the interplay of participants (Watt et al. 2010). To this end can contractor competitiveness be measured effectively (Yan 2011; Wong et al. 2000), and the multi-criteria approach be operated smoothly for value of money (Drew, Skitmore 1992; Liu et al. 2016).

\subsection{A contractor perspective}

In the domain of competitive bidding, decision that contractors make comprises two stages, namely bid/not to bid and marginal sizes (Ye et al. 2014; Egemen, Mohamed 2005). In these two stages, the client and contractors are often faced with a zero-sum game where each one's gain or loss of utility is balanced by the other's loss or gain of utility. A higher marginal-size decision made by contractors will reduce the total amount of interest available for the client. In contrast, non-zero-sum game elaborates a situation in which the interacting parties' aggregate gains can be larger than zero-sum (Wright 2000). The client and contractors are not dual-antagonistic in the non-zero-sum game, and they can enlarge common interests by way of close cooperation. Both of them have same responsibility of creating values in the way towards non-zero-sum paradigms, rather than embarking on their own benefits without considering others.

As shown in Table 1, academic attention paid to the subject of competitive bidding has been increasing over the past decades. It is noted that previous studies are largely concerned with multiple criteria, decision-making and competitiveness evaluation; most of them are addressed from the client's perspective, but interests of contractors have rarely been interpreted. For examples, Oo et al. 
Table 1. A list of relevant studies on competitive tendering

\begin{tabular}{|c|c|c|c|c|c|c|c|}
\hline \multirow{2}{*}{ No } & \multirow{2}{*}{ Reference } & \multicolumn{2}{|c|}{ Perspective } & \multicolumn{4}{|c|}{ Keywords } \\
\hline & & Client & Contractor & Criteria & Competition & Decision & Evaluation \\
\hline 1 & Hatush and Skitmore (1997) & $*$ & & $*$ & & & $*$ \\
\hline 2 & Hatush and Skitmore (1998) & $*$ & & & & & * \\
\hline 3 & Egemen and Mohamed (2005) & $*$ & & * & & & $*$ \\
\hline 4 & Oo et al. (2008) & & $*$ & & & $*$ & \\
\hline 5 & Arslan et al. (2008) & & & $*$ & & & $*$ \\
\hline 6 & Watt et al. (2009) & $*$ & & $*$ & & & $*$ \\
\hline 7 & Watt et al. (2010) & $*$ & & $*$ & & & $*$ \\
\hline 8 & Cheng et al. (2011) & & $*$ & $*$ & & $*$ & \\
\hline 9 & Liu et al. (2013) & * & & * & & & * \\
\hline 10 & Ye et al. (2014) & & $*$ & * & & $*$ & \\
\hline 11 & Zhang et al. (2015) & $*$ & & & & & $*$ \\
\hline 12 & Liu et al. (2016) & $*$ & & $*$ & & $*$ & $*$ \\
\hline 13 & Yang et al. (2016) & * & & $*$ & & & $*$ \\
\hline 14 & Liu et al. (2017) & $*$ & & $*$ & & & $*$ \\
\hline 15 & Biruk et al. (2017) & & $*$ & & & $*$ & \\
\hline
\end{tabular}

(2008) compared contractors' decision to bid in Hong Kong and Singapore. Hong Kong contractors are more influenced by market conditions in their decision to bid than Singaporean contractors, independent of the intensity of competition. Contractors from both cities tend to have less bidding decision when the number of competitors in the tender bidding increases. Biruk et al. (2017) examined contractors' bidding decisions and identified key factors for contractors' bidding decisions. Top five decision factors include: 1) Client's financial standing; 2) Conditions of entering the bidding procedure; 3 ) Possibility of further cooperation with the client after the successful completion of project; 4) Experience/relationships with the project team (designer and client); 5) Project size and scope. To further investigate the rationales behind markup decision of the contractors for different types of projects, Ye et al. (2014) identified three main decision factors of markup: i) project nature; ii) client characteristic; and iii) market environment. Cheng et al. (2011) integrated various approaches, including fuzzy preference relations, multi-criteria prospect model and cumulative prospect theory to develop a bidding decision model and provide optimal markup scale advices to contractors. Despite these efforts, a couple of issues remains unsolved in the construction industry: 1) Does it mean that contractors have no need to participate in the formulation of competitive bidding?; 2) How can contractors' concerns be tightly embedded in the multi-criteria approach?

The participation of contractors in construction competition is to win some contracts to undertake in the future. However, they might dislike those projects that the client poses very strict requirements on contractors with unreasonable schedules, unrealistic prices, and overwhelming quality challenges. Once a large number of contractors determine not to get involved in bidding, insufficient competition will arise, and the bidding process has to be relaunched. Consequently, the perception, attitudes and responses of contractors towards tender evaluation criteria deserve much consideration in the formulation of competition rules.

\subsection{Contractors' perceptions on the competition rule}

As discussed above, it is essential for contractors to evaluate the extent to which the client's requirements and expectation are absorbed in the formulation of competition rules. The perception of contractors on tender evaluation criteria is arguably determined by their experience, knowledge, expertise, information, and preference. A small contractor firm will find it easier than a large one to realize their perceptions in this sense and make relevant decisions on bidding. Shash (1993) argued that the contractor could decide a markup size that increases the chance of achieving a dominating criterion of the competition. If the price factor occupies the competition rule, each bidder will attempt to offer a price that maximizes the probability of winning the tender and minimizes the differences between his/her bid and the bid prices of rival competitors. Kim and Reinschmidt (2011) argued that risk attitude is 
Table 2. Difference between public and private projects in attributes

\begin{tabular}{|c|c|c|c|c|}
\hline No. & Attributes & Public projects (PUs) & Private projects (PIs) & References \\
\hline A1 & Accountability & Highly required & Neutral & $\begin{array}{l}\text { Drew and Skitmore (1997) } \\
\text { Holt et al. (1995) }\end{array}$ \\
\hline $\mathrm{A} 2$ & Application of lowest price & Less frequent & Frequent & Drew and Skitmore (1992) \\
\hline A3 & Bidding methods & Competitive & Selective /competitive & Drew and Skitmore (1992) \\
\hline A4 & Business environment & Complicated & Less & Newcombe (1990) \\
\hline A5 & Competitive environment & Broad & Narrow & Newcombe (1990) \\
\hline A6 & Construction risks & More & Less & Newcombe (1990) \\
\hline A7 & Cost control & Neutral & Highly required & Hwang et al. (2011) \\
\hline A8 & Design and specification & Detailed & Simplified & Drew and Skitmore (1992) \\
\hline A9 & Diversity of works & Higher & Lower & Drew and Skitmore (1992) \\
\hline A 10 & Influence to the society & More & Less & Ye et al. (2014) \\
\hline A11 & Motivation & For social welfare & For profits & Hwang et al. (2011) \\
\hline A12 & Profitability & Expected & Highly expected & Holt et al. (1995) \\
\hline A13 & Project characteristics & Complicated & Simplified & Ye et al. (2014) \\
\hline A14 & Requirements of the client & Higher & Median & Fu et al. (2003) \\
\hline A15 & Schedule control & Neutral & Highly required & Hwang et al. (2011) \\
\hline A16 & Social concern & Higher & Lower & Ye et al. (2014) \\
\hline A17 & Tendering procedure in comparison & Inflexible & Flexible & Drew and Skitmore (1997) \\
\hline
\end{tabular}

a significant factor determining competitive characteristic of contractors. A moderate risk aversion is associated with higher survival rates, higher profitability, and firm growth. Ballesteros-Pérez et al. (2016) found that the traditional lowest bid method promotes bidding aggressiveness of bidders and, all the negative outcomes associated with aggressive bidding. Factors, including bid score weighting, bid scoring formula, and abnormally low bids criterion are considered significant in affecting behavior of bidders, e.g. aggressive/conservative bidding and concentration/ dispersion of bids. As shown in Table 2, two types of projects - public and private are compared in a few manners, offering a useful angle to view how contractors perceive the competition rule in their own right. Therefore, project attributes are assumed to influence the perception of contractors on the competition rule (i.e. tender evaluation criteria).

The seventeen (17) attributes listed in Table 2 are grouped into four stages (see Figure 1) in light of their inherent connections, namely: 1) briefing; 2) bidding; 3) im- plementation; and 4) post-project review. The briefing stage refers to those activities related to project inception and construction plans. The bidding stage describes the interaction between the client and contractors to reach a contract. The implementation stage means the construction process conducted as said in construction plans. The post-project review serves to evaluate the construction process after the project is put into use. The classification of attributes into these four stages was conducted by firstly reviewing the nature, characteristics and the relationship in various project stages of these 17 factors discussed and identified in previous literature (Newcombe 1990; Holt et al. 1995; Drew, Skitmore 1992, 1997; Fu et al. 2003; Hwang et al. 2011; Ye et al. 2014). To ensure the suitability of the attribute classification, it was cross-checked by the industry practitioners and academics.

The competition rule stipulated in tender documents may be given a certain level of importance by either public or private clients along the four stages. Currently, the approach of integrated project delivery has gained much
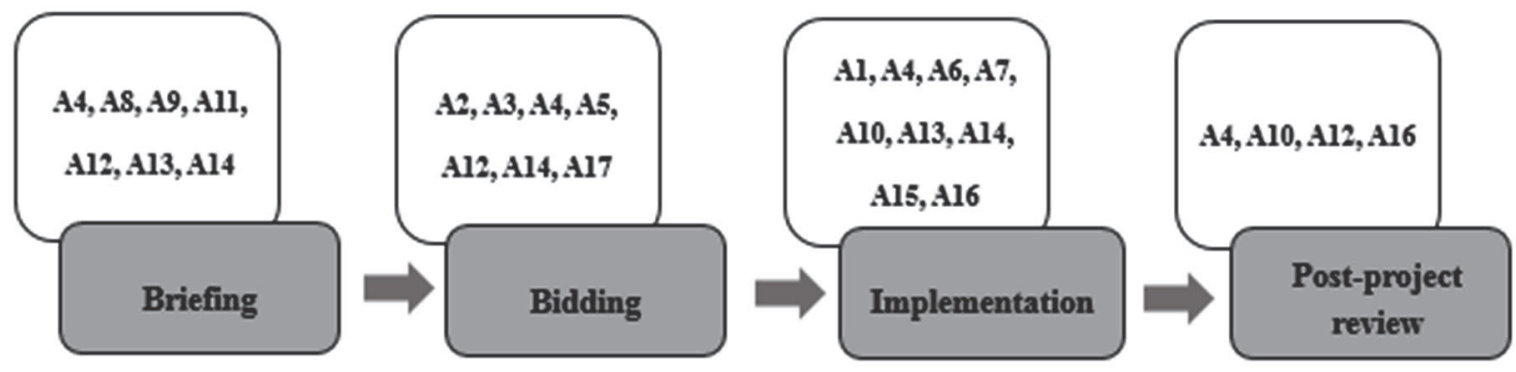

Figure 1. Four stages of determinant factors 
popularity as an efficient assembly of production factors (i.e., people, technology, information and capitals) in the construction process (Mesa et al. 2016). An aggregating application of this delivery approach necessitates contractors to develop an ability of providing holistic services to the client, and both the client and contractors ought to work together in the whole process (Mesa et al. 2016). Therefore, it is vital that the competition rule is built on all of the four stages.

\section{Methodology}

A mixture of research methods was adopted in this study to serve the aforementioned research purpose. First, an extensive literature review and content analysis on used tender documents gave rise to the identification of 34 evaluation factors. Second, a questionnaire survey was conducted to collect professionals' opinions on the importance of these factors. Third, data were collected and analyzed to detect the key factors and their differences between public and private projects.

\subsection{Identifying tender evaluation factors}

Typical databases including Web of Science, Engineering Village, Emerald, and ASCE Library were scanned carefully to identify academic publications on the multi-criteria approach. The technique of content analysis was adopted to extract tender evaluation factors (EFs) outlined in previous studies. The content analysis process started with the analysis and coding of information from sources abovementioned jointly by the authors and research assistants. Participants were trained and given ten randomly selected and identical items and made an initial analysis in an independent way. Participants' judgments were compared, and disagreements were discussed until agreements were reached. Inter-coder reliability was $97 \%$ of all the items coded, which is considered acceptable (Kassarjian 1977). The coders subsequently analysed the rest of items, coding a total of fifteen data items. Participants were then invited to re-analyse $5 \%$ of the items and the test-retest agreements are $99 \%$. At the end, a total of $27 \mathrm{EFs}$ were framed. For simplicity, only the results are shown in Table 3.

The national government of China has enforced a template for the client to compile tender documents for a long time. The template can be transformed into any type of tender documents to satisfy various needs. On the basis of the template, the client is able to state clearly project profiles, tendering procedures, qualification of tenderers, components of tenders, project delivery goals, risk sharing, and schedule for tendering. Therefore, tender documents are a proxy for observing the client's efforts in the formulation of competition rule. In this study, 217 tender documents covering a wide range of construction projects (i.e., housing, infrastructure, renewal public projects) were gathered. All of the tender documents are built on the multi-criteria approach. The technique of content analysis was used again to extract those factors that have been considered in tender evaluation criteria. Steps of content analysis process as described above were conducted twice by the research team to avoid subjectivity and information omission. The rule for inclusion is that a factor should be included if it appears in more than two tender documents. The frequency per EF in the 217 tender documents is given in Table 3.

\subsection{Questionnaire survey}

Evaluating relative importance is an effective way to identify key factors from a number of alternatives (Ye et al. 2014). A five-point Likert scale (5 - extremely important, 4 - important, 3 - neutral, 2 - unimportant, 1 - extremely unimportant) is often adopted to gather respondents' opinions. In this study, 34 factors were converted into a questionnaire with three sections. The first section describes the objectives and scope of the survey. In the second section, respondents are requested to provide demographic information regarding types and qualifications of enterprises, education background and working years. The other part of the questionnaire is a scale for respondents to mark importance levels on all factors. In this section, all factors are tabulated with two columns (public projects and private projects), and respondents are reminded to fill in both columns per factor.

500 copies of questionnaire were sent out via post or e-mail. To ascertain a good response rate, respondents were contacted by phone as far as the research team was able to. A total of 275 questionnaires were finally returned, giving a response rate of $55 \%$. However, 68 copies of questionnaires were found inadequate due to incomplete answering. The respondents distribute widely on working years: $0-2$ years (9.63\%), 3-5 years $(25.67 \%), 6-10$ years $(32.62 \%), 11-15$ years $(16.58 \%)$, and over 16 years $(15.51 \%)$. Most of them (68.61\%) indicated good knowledge of the subject. The respondents were from major cities of China, namely Beijing (8.02\%), Shanghai (7.49\%), Guangzhou (10.16\%), Chengdu (13.90\%), Chongqing (12.83\%), Hangzhou (8.56\%), and Nanjing (8.02\%). They were general contractors (69.52\%), subcontractors $(11.23 \%)$, tendering agents $(3.21 \%)$, and others (16.04\%). Of all the respondents, $18.5 \%$ are high-level enterprise managers, $36.3 \%$ are project managers, and $45.2 \%$ are commercial managers in charge of bidding activities.

\subsection{Data analysis}

Mean values (MVs) per evaluation factor (EF) were calculated in both two columns - public and private, and the results are then used to rank all the factors in a descending order of importance. According to the definition of the five-point Likert scale, those items with an importance level of MV higher than 3.0 can be included. In considering that this step cannot derive crucial items, the Pareto law was adopted further to extract key evaluation factors (Chen et al. 1994). According to the Pareto law, 20 percent of factors contribute to 80 percent of all factors in importance. As a rule of thumb, the range of MVs of all the important EFs is $\left(V_{2}, V_{1}\right)$, and $V_{1}>V_{2}>3.0$. The larger 
Table 3. A preliminary list of tender evaluation factors

\begin{tabular}{|c|c|c|c|}
\hline No. & Evaluation Factors (EFs) & Sources & Frequency \\
\hline EF1 & Bid price & $\begin{array}{l}\text { Hatush and Skitmore (1998) } \\
\text { Watt et al. (2009) }\end{array}$ & 217 \\
\hline EF2 & Bid quality & Watt et al. (2009) & 21 \\
\hline EF3 & Bidders' honors and awards & Watt et al. (2009) & 50 \\
\hline $\mathrm{EF} 4$ & Bidders' performance in the past & Ng and Skitmore (1999) & 111 \\
\hline EF5 & Bidders' additional offers & / & 6 \\
\hline EF6 & Competence of the project manager to be appointed & Watt et al. (2009) & 73 \\
\hline EF7 & Competitiveness of bidders & Ng and Skitmore (1999) & 73 \\
\hline EF8 & Completeness of bid components & I & 16 \\
\hline EF9 & Comprehension of project management team on tender documents & I & 24 \\
\hline EF10 & Construction plan & Watt et al. (2009) & 96 \\
\hline EF11 & Construction site layout & Watt et al. (2009) & 108 \\
\hline EF12 & Construction technical measures & Ng and Skitmore (1999) & 156 \\
\hline EF13 & Credit rating of bidders & Ng and Skitmore (1999) & 74 \\
\hline EF14 & Dealing with unanticipated problems (caused by weather) & Wong et al. (2001) & 27 \\
\hline EF15 & Degree of innovation & Tang et al. (2003) & 30 \\
\hline EF16 & Health, safety and environmental measures & Watt et al. (2009) & 167 \\
\hline EF17 & Manpower, plant and equipment capacity & Watt et al. (2009) & 158 \\
\hline EF18 & Onsite energy-saving measures & I & 26 \\
\hline EF19 & Organizational experience and skills & $\begin{array}{l}\text { Hatush and Skitmore (1997) } \\
\text { Watt et al. (2009) }\end{array}$ & 134 \\
\hline EF20 & Overhead fee & Hatush and Skitmore (1997) & 21 \\
\hline EF21 & Past relationship with other entities & Nieto-Morote, Ruz-Vila (2012) & 16 \\
\hline EF22 & Proposed schedule & Lambropoulos (2013) & 15 \\
\hline EF23 & Protection for completed construction works & / & 15 \\
\hline EF24 & Quality assurance and control & Ng and Skitmore (1999) & 175 \\
\hline EF25 & Quality of construction samples & / & 6 \\
\hline EF26 & Reasonableness of bid and its components & Wong et al. (2001) & 22 \\
\hline EF27 & Recommendations on the improvement of project management & / & 20 \\
\hline EF28 & Response to instruction for bidders & $\begin{array}{l}\text { Ng and Skitmore (1999) } \\
\text { Watt et al. (2009) }\end{array}$ & 50 \\
\hline EF29 & Schedule assurance and control & Watt et al. (2009) & 180 \\
\hline EF30 & Subcontracting management & Ng and Skitmore (1999) & 29 \\
\hline EF31 & Technical solution to key issues & Liu et al. (2016) & 53 \\
\hline EF32 & Timely payment to workers & Arslan et al. (2008) & 3 \\
\hline EF33 & Unit price of bid & Wong et al. (2001) & 25 \\
\hline EF34 & Warranty offered & Lambropoulos (2013) & 52 \\
\hline
\end{tabular}

the MV, the more important the EF; and the MVs of key EFs fall in an interval between $\chi$ to $V_{1}\left(V_{1} \geq \mathrm{MV} \geq \chi\right)$. The equation for calculation is described below:

$$
\frac{V_{1}-\chi}{V_{1}-V_{2}} \times 100 \%=20 \%,
$$

where $V_{1}$ represents the highest mean value; $V_{2}$ represents a mean value larger than 3.0 , and $\chi$ represents the lowest mean values.
There might be some key evaluation factors in common for both public and private projects. It is important to explore whether these factors have same roles in the competition rules. Therefore, on the basis of the key factors, the Hotelling's T (HT) test was conducted to detect all of the common key EFs between PUs and PIs. The distribution of HT is a generalization of Student's $t$ distribution used to evaluate the statistical significance of the difference between samples' means (Ye et al. 2014). HT test applies 
to multivariate statistics, indicating the difference between multivariate means of different samples, which contains one sample $t$ test, paired $t$ test, and two samples $t$ test. Two tests were conducted namely independent samples $t$ test to reflect the normality and homogeneity of variances, and multivariate paired $t$ test to image the difference per EF between public projects (PUs) and private projects (PIs) in importance.

Three preconditions shall be satisfied if HT test is to be adopted. First, data for analysis are consecutive. Second, data match the normal distribution. Third, sample variances must be homogeneous. Therefore, data conversion, normality test and homogeneity test of variances were conducted accordingly. The purpose of conducting reliability test is to look at whether respondents' answers to the 187 questionnaires are consistent with each other. As calculated, the Cronbach's Alpha coefficients for PUs and PIs are 0.950 and 0.959 , suggesting that both have a satisfactory level of reliability.

Respondents' judgments on a factor were grouped into paired samples: Group 1 - PU, Group 2 - PI. The returned questionnaires were classified into 19 groups according to the city that respondents belong to. Mean value per $E F$ per group was computed using the following equation. Thereby, the mean values derived follow a continuous distribution on the range $(1,5)$ can be confirmed:

$$
x_{i j k}=\frac{\sum_{\mathrm{m}=1}^{\mathrm{n}} x_{i j}}{n} ; i=1,2 ; j=1,2, \ldots, 34,
$$

where, $x$ refers to the score of importance level for a factor:

$i=1$ or 2 , represents public projects and private project respectively;

$j=1,2,3, \ldots, 34$, refers to the number of a key factor in ranking, as shown in Table 3;

$k=1,2,3, \ldots, 19$, represents the number of a city in ranking;

$n$ means the total amount of samples from a certain city group.

Data conversed as described above were restructured into two matrixes $(34 \times 19)$ - PUs and PIs. Each EF has 19 mean values to test whether the mean values obey the normal distribution. The test is built on Kolmogorov-Smirnov $(K-S)$ coefficients of 68 samples. If $\mathrm{P}$-value of the sample is larger than 0.05 , the data can satisfy the normal distribution. Furthermore, the Levene test of variance equations was detected to measure the variances between $X_{1 j}$ and $X_{2 j}$. The structured mean values state whether this EF has significantly indifferent variances. If $\mathrm{P}$-value of Levene test for $X_{1 j}$ and $X_{2 j}$ is larger than 0.05 , the EF has significantly indifferent variances between the two groups.

\section{Results}

Mean values for all EFs are listed in Table 4 and they are ranked in a descending importance-based order. $\chi$ was calculated using equation 1 . As a result, $4.284 \geq \mathrm{MV} \geq$
3.222 for public projects, and MVs of the key EFs range from 4.072 to $4.284 ; 4.259 \geq \mathrm{MV} \geq 3.062$ for private projects, and MVs of the key EF range from 4.020 to 4.259. The results suggest that both public and private projects have eleven key factors, and there are nine items in common as indicated in Table 4.

In the step of HT test, P-values of $K$-S coefficients for $X_{1 j}$ range from 0.168 to 0.988 , and the same values for $X_{2 j}$ range from 0.195 to 0.999 . All of the $K-S$ coefficients are larger than 0.05 , indicating that both $X_{1 j}$ and $X_{2 j}$ obey normal distribution. P-values of Levene test for either $X_{1 j}$ or $X_{2 j}$ range span from 0.079 to 0.996 . All are larger than 0.05 , suggesting that each has significantly indifferent variance between PUs and PIs. Hence, the data collected for the nine key factors are qualified to conduct the multivariate paired HT test.

The multivariate paired HT test is decomposed of two steps, namely the paired samples correlation coefficient $r$ and the paired samples HT test P-values. If $0.5 \leq|r|<0.8$, the two variables compared are moderately correlative. In this study, $82.35 \%$ absolute values of the paired samples correlation coefficients are larger than 0.5 with a significance level lower than 0.05 , suggesting that these variables are significantly correlative. If P-value of the paired samples is smaller than 0.05 , this factor plays different roles in the competition rules between public and private projects. In reverse, if $\mathrm{P}$-value is larger than 0.05 , the role is same. In this study, the results of the paired samples HT test $(r$, sig., $P)$ are as follows: $\mathrm{EF} 10(0.754,0,0.025), \mathrm{EF} 13(0.728,0$, $0.008)$, EF22 (0.891, 0, 0.035), EF26 (0.789, 0, 0.034), EF32 (0.834, 0, 0.038), EF12 (0.407, 0.084, 0.643), EF24 (0.829, $0,0.218), \operatorname{EF} 33(0.644,0.003,0.373)$, and EF34 (0.569, $0.011,0.253)$.

\section{Findings and discussion}

\subsection{A new perspective on the competition rule}

As listed in Table 4, the common key evaluation factors (EFs) for both public and private projects are found to contain EF10 (Construction plan), EF12 (Construction technical measures), EF13 (Credit rating of bidders), EF22 (Proposed schedule), EF24 (Quality assurance and control), EF26 (Reasonableness of bid and its components), EF32 (Timely payment to workers), EF33 (Unit price of bid), and EF34 (Warranty offered). In addition, two EFs are appreciated valuable for public projects (EF7, Competitiveness of bidders; EF8, Completeness of bid components), and two for private projects (EF1, Bid price; EF29, Schedule assurance and control). The detection of these key factors outlines a pattern that contractors employ to view the competition rule, and the pattern vary slightly between public and private sectors. Therefore, this study contributes to the body of knowledge by addressing a new perspective on competitive bidding in the discipline of construction economics and management (Wong et al. 2001; Ye et al. 2014). The implication is that although competitive bidding is dominated by the client, contrac- 
Table 4. A MV based list of factors in descending order

\begin{tabular}{|c|c|c|c|c|c|c|c|}
\hline \multicolumn{4}{|c|}{ Public Projects (PUs) } & \multicolumn{4}{|c|}{ Private Projects (PIs) } \\
\hline $\mathrm{EF}$ & MV & $\mathrm{EF}$ & MV & $\mathrm{EF}$ & MV & $\mathrm{EF}$ & MV \\
\hline $\mathrm{EF} 13^{* \star}$ & 4.284 & EF6 & 3.983 & $\mathrm{EF} 22^{\star *}$ & 4.259 & EF16 & 3.905 \\
\hline EF7 & 4.277 & $\mathrm{EF} 2$ & 3.915 & $\mathrm{EF} 33^{* *}$ & 4.182 & EF11 & 3.893 \\
\hline $\mathrm{EF} 32^{\star *}$ & 4.257 & EF4 & 3.907 & EF1 & 4.151 & EF18 & 3.859 \\
\hline $\mathrm{EF} 33^{* *}$ & 4.248 & $\mathrm{EF} 27$ & 3.902 & $\mathrm{EF} 12^{\star *}$ & 4.125 & $\mathrm{EF} 30$ & 3.842 \\
\hline $\mathrm{EF} 10^{* *}$ & 4.207 & EF30 & 3.888 & EF29 & 4.121 & EF19 & 3.829 \\
\hline $\mathrm{EF} 24^{\star *}$ & 4.201 & EF17 & 3.863 & $\mathrm{EF} 24^{\star *}$ & 4.118 & $\mathrm{EF} 27$ & 3.820 \\
\hline $\mathrm{EF} 12^{\star *}$ & 4.175 & EF20 & 3.857 & $\mathrm{EF} 32^{* *}$ & 4.106 & $\mathrm{EF} 21$ & 3.803 \\
\hline $\mathrm{EF} 26^{* *}$ & 4.162 & EF21 & 3.850 & $\mathrm{EF} 34^{\star *}$ & 4.069 & EF14 & 3.792 \\
\hline $\mathrm{EF} 34^{* *}$ & 4.156 & EF11 & 3.849 & $\mathrm{EF} 10^{\star *}$ & 4.047 & $\mathrm{EF} 20$ & 3.791 \\
\hline EF8 & 4.125 & EF18 & 3.840 & $\mathrm{EF} 13^{* *}$ & 4.040 & $\mathrm{EF} 2$ & 3.784 \\
\hline $\mathrm{EF} 22^{* *}$ & 4.122 & EF25 & 3.832 & $\mathrm{EF} 26^{* *}$ & 4.030 & EF23 & 3.769 \\
\hline EF19 & 4.053 & EF23 & 3.811 & EF28 & 4.004 & EF4 & 3.754 \\
\hline EF29 & 4.045 & EF15 & 3.762 & EF31 & 4.001 & EF25 & 3.753 \\
\hline EF31 & 4.041 & EF14 & 3.725 & $\mathrm{EF} 17$ & 3.997 & EF15 & 3.569 \\
\hline $\mathrm{EF} 1$ & 4.033 & EF9 & 3.566 & EF8 & 3.966 & EF5 & 3.552 \\
\hline EF16 & 4.022 & EF3 & 3.251 & EF6 & 3.927 & EF9 & 3.523 \\
\hline EF28 & 3.991 & EF5 & 3.222 & EF7 & 3.911 & EF3 & 3.062 \\
\hline
\end{tabular}

Note: those items underlined mean that they are crucial to both public and private projects. ${ }^{* *}$ represents the common key factor for both public (PUs) and private (PIs) projects.

tors' awareness, thoughts, and attitudes are associated with the efficiency of the competition rule. The gap between the client and contractors exists in the construction industry, suggesting that more efforts should be made to improve current competitive bidding practices in order to yield win-win effects to both the client and contractors.

The whole construction process is divided into four stages, namely briefing, bidding, implementation, and post-project review (see Figure 1) with reference to construction project attributes. In order to explore the opinions of contractors on the competition rule, all of the key factors are scattered over these four stages (as indicated in Figure 2) according to the nature, characteristics and the effect on various project stages. As shown in Figure 2, most of the key factors are stuck in the stage of bidding (EF13, EF26, EF33) and implementation (EF10, EF12, EF24,
EF22, and EF32), while there is only one EF for the postproject review stage (EF34). It is thus found that the attributes of construction projects have not been fully absorbed in the formulation of competition rules. Whilst contractors are advocated to develop all-round perceptions on the competition rule, the gap of tender evaluation criteria between the client and contractors must be filled in. Thereby, the cooperation between the client and contractors will be more fruitful in delivering construction projects.

\subsection{Using indifferent factors to fortify contractor competitiveness}

The results suggest that four key factors, namely EF12 (Construction technical measures), EF24 (Quality assurance and control), EF33 (Unit price of bid), and EF34

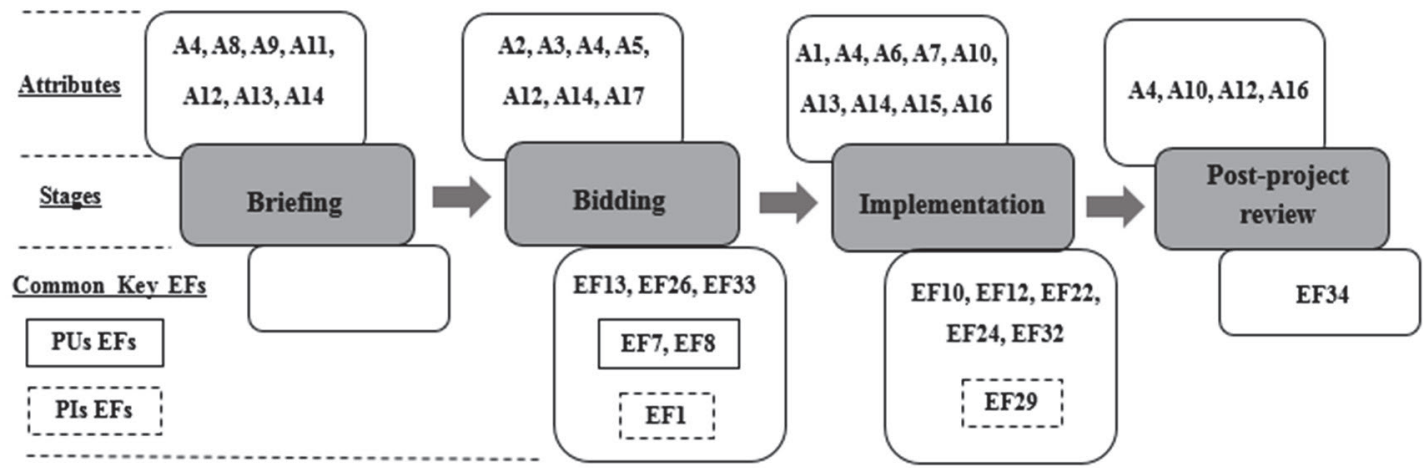

Figure 2. Distribution of key factors along the construction process 
(Warranty offered) have indifferent roles in the competition rules for both public and private projects. These factors are discussed here with an aim of elaborating their meanings and implications to practitioners. Contractors have to adopt flexible response strategies and optimize the portfolio of resources to maintain competitiveness in various competition situations. However, not all contractors are able to achieve this. In view of the relatively unchanged roles, contractors are recommended to input more resources into these four factors to fortify competitiveness in the long run.

Unit price of bid (EF33): This factor spells out the importance that contractors attach to economic interest in the competition rule for both public and private projects. Competitive bidding enables the client to reach either lump-sum or unit-price agreements with contractors prior to signing construction contracts. In this step, bid prices and unit prices are main issues to be negotiated between the client and contractors. To gain more advantages over price competition, contractors must examine tender documents carefully, to give an accurate estimation of bidding prices, and to compile tenders in due ways. Since tender evaluation is time-consuming, the client usually spends much time collecting information about unit price of bid to lay a foundation for comparing bidders' prices. A negotiation on unit price of bid is to allocate risks reasonably between project participants. The lower is the bid price, the higher the competitiveness. Therefore, economic interest prevails in both public and private construction projects in a similar way.

Construction technical measures (EF12), Quality assurance and control (EF24): The identification of these two factors highlights the vital role of construction quality and its realization that contractors have to accomplish on construction sites. In the implementation stage, construction ideas are transformed into physical facilities, and construction activities are subject to technical uncertainties and risks especially in infrastructure projects such as tunnels, dams, and bridges. It is highlighted that $29 \%$ of construction project accidents in Germany are directly caused by quality problems. Similarly, China had 442 cases of construction quality and safety production accidents in 2015, in which 554 people died. Construction technical measures serve to solve problems and difficulties and improve production efficiency; quality assurance and control is intended to guarantee that project achievement matches the client's requirements. Therefore, previous studies have pointed out that competence in technology and management abilities are two key indicators for the client to evalu- ate a contractor's competitiveness (Liu et al. 2016). Meanwhile, contractors have many choices of demonstrating their technical capability via track record, proposing good construction technical measures, providing quality assurance + control, and offering construction organization designs (Ng, Skitmore 1999; Liu et al. 2016).

Warranty offered (EF34): Inappropriateness and problems with completed construction projects have been aware industrywide in China, which necessities the creation of warranty services as a solution. In effect, technical complexity of construction projects inspires the client to include the strength of contractors in supplying warranty services in the competition rule. For instance, warranty provision has been a part of US construction contracts to benefit the client from increasing the quality of built facilities (Lambropoulos 2013; Bayraktar et al. 2004). In China, the warranty period normally lasts two or three years. The inclusion of this factor in the competition rule is also originated from the fact that sustainability and lifecycle management paradigms are elaborated at the outset of construction projects and gradually incorporated into the construction process (Labuschagne, Brent 2005). The post-project warranty provided by contractors can improve the satisfaction of both the client and end-users, and it could be a valuable way to build trust between the client and contractors. Figure 3 summarised these four abovementioned common factors and their related stages in light of their inherent connects.

\subsection{Utilizing different factors to diversify the competition rule}

The results of data analysis signify contributions of five factors to the competition rule in different ways, namely EF10 (Construction plan), EF13 (Credit rating of bidders), EF22 (Proposed schedule), EF26 (Reasonableness of bid and its components), and EF32 (Timely payment to workers). These factors are concerned with bidding (EF13, EF26) and implementation (EF10, EF22, EF32) of construction activities, and can explain the reality that finding an unchanged competition rule for all kinds of projects is unrealistic. These factors are discussed herein by referring to the project attributes shown in Figure 4.

Credit rating of bidders (EF13), Reasonableness of bid and its components (EF26): Credit and reputation are utilized to gauge contractors' future performance based on an analogy from their track record in the past. As a key competitiveness factor, credit reflects the achievements of organizations as a result of corporate governance structure

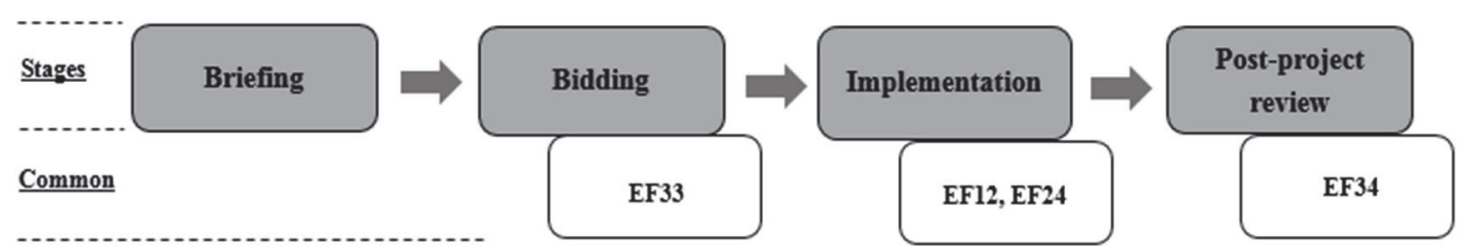

Figure 3. Common key factors of the competition rule 


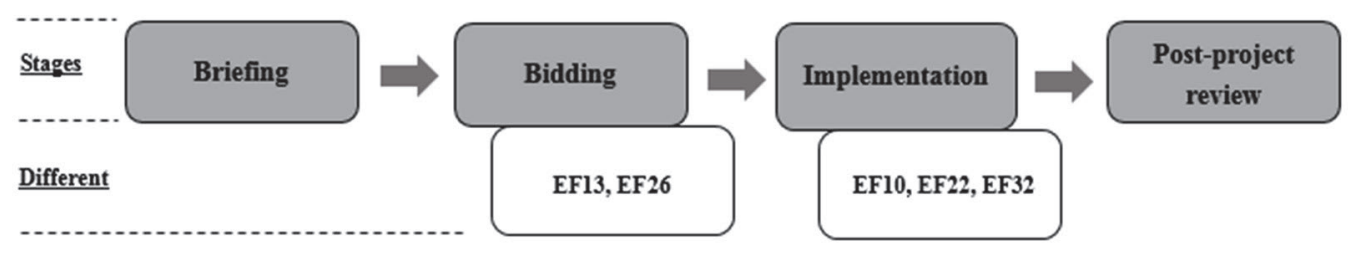

Figure 4. Different factors of the competition rule

(Bereskin et al. 2015). Contractors with higher credits are more able to receive supports from financers (Bereskin et al. 2015). The different role that this factor plays in the competition rule between public and private projects can be ascribed to project attributes. Table 2 shows that public projects are enclosed by a more intricate business environment (A4), competitive environment (A5), higher requirements of the client (A14), and huger investment demand than private projects. For transparency, information about the credit of contractors is often compiled to aid governments in evaluating the quantification of contractors.

In the exercise of tender evaluation, bids are examined carefully and benchmarked if needed (Watt et al. 2010). This study found that the client's efforts revolve round bid prices, reasonableness of bids and its components. Bid price is one of the primary competitiveness indicators (Zhang et al. 2015; Liu et al. 2016); the reasonableness of bid and its components images contractors' robust consideration on the construction works they are to bid for. Drew and Skitmore (1997) pointed out that tendering procedures for public projects are often standardized by governments at various levels, and its implementation is under strict supervision. Due to inherent governance, public projects are regulated with more inflexible tendering procedure (A17), more competitive bidding methods (A3) and less application of lowest price criteria (A2). It is implied that the client of public projects should guide contractors to examine the list item carefully and offer reasonable bid prices.

Construction plan (EF10), Proposed schedule (EF22), Timely payment to workers (EF32): Construction plan functions as a roadmap for contractors to undertake construction works. Its importance as revealed in this study drives the client to elaborte it in tender documents. In practice, contractors have many opportunities to handle construction challenges such as tighter schedule, higher requirements on sustainable construction and social responsibility on construction sites. A good construction plan proposed in tenders demonstrates contractors' effort to strike the tradeoff between cost, time and quality. Public projects in nature are characterized by higher accountability (A1), vulnerability to societal impact (A16), project complexity in technologies (A13), and construction risks exposure (A6). Therefore, the client in the public sector has to examine whether construction plans are formulated in due manners.

One of the responsibilities of contractors is to complete construction works within a defined timeframe (Wu et al. 2010). More resources are consumed and construction quality might be impacted if a construction project falls behind the schedule. As revealed in the study, part of the competition rule is thus built on the factor of proposed schedule (EF22), which means that contractors need to express strong determination to deliver construction projects timely. Furthermore, it is found that strategies to manage this factor should not be same between in the public sector and in the private one. The reason has been offered in the literature. As presented in previous studies, the priority of project management triangle in public projects is quality $>$ cost $>$ time, but it is time $>$ quality $>$ cost in private projects (Holt et al. 1995). It seems that the public client cares more about construction quality control, while the private client stresses schedule control (A15) (Hwang et al. 2011).

The contribution of construction workers to economic prosperity has never faded over the past decades. However, construction workers are vulnerable and in shortage of adequate education and training (Torres et al. 2013). Salary payment to construction workers might be misleading, and it can develop into some kinds of social problems. If this happens, the client and contractors may be fined heavily. Therefore, it is necessary to embed this factor "timely payment to workers" (EF32) in the competition rule and requires contractors to compete with good offers. By comparison, the public sector has more far-reaching influence to society (A16), and they have more obligations to ensure that timely payment to laborers has been made efficiently.

\section{Conclusions}

In the construction market, business is transacted between the client and contractors. The mechanism of construction business transaction is mostly by virtue of the multicriteria approach, of which tender evaluation criteria constitute the competition rule. In practice, the complexity of construction projects usually confronts the client with difficulty in devising a competition rule acceptable to contractors. This study highlights a new perspective on the competition rule by examining what contractors really want and how to improve the competition rule if their opinions are raised. It is found that the crucial part of tender evaluation criteria for both public and private projects is similarly composed of eleven key factors respectively. Among the factors, nine items are overlapped, namely credit rating of bidders, reasonableness of bid and its components, construction plan, timely payment to workers, proposed schedule, unit price of bid, construction technical measures, quality assurance and control, and warranty offered. Furthermore, part of the overlapped factors in the 
competition rule differ from each other between public and private projects. The difference can be ascribed to the attributes of project types. The implications are that contractors may consider using those common factors to improve competitiveness, and the client utilizes different factors to diversify the competition rule. Thereby, effective competition can be actualized in the implementation of the multi-criteria approach.

Despite these achievements, this study was limited by its designed boundaries. Firstly, although the 207 valid responses and the 55 per cent response rate are considered reasonable when compared with previous studies, this study presented an earliest effort to investigate the perceptions of competition rule in the construction industry. To generalize the findings, a larger sample size with contractors of different backgrounds (e.g. ENR contractors, state-/ government-owned contractors, private contractors, from more cities in China) would be expected in any further study. Secondly, while this study provides a preliminary insight into the competition rule for public and private projects, but it does not provide any findings on how contractors reacts to competition rules in different project/ procurement types. Future studies should be extended to not only investigating based on a larger sample size but also to examining the acceptability of competition rules under different project types and procurement methods in China or any other regions.

\section{Author Contributions}

As the principal investigator of this project, Dr Kunhui Ye was responsible for everything including the conception, design and development of the data analysis. Ms. Dan Zeng was responsible for data collection and analysis. Dr Johnny Wong were responsible for literature review and data interpretation. All of them worked together in drafting this paper.

\section{Funding}

This work was supported by Chongqing University under Grant No. 106112016 CDJSK 03 XK 08.

\section{Disclosure Statement}

The authors would like to declare that they no competing financial, professional, or personal interests from other parties.

\section{References}

Arslan, G.; Kivrak, S.; Birgonul, M. T.; Dikmen, I. 2008. Improving sub-contractor selection process in construction projects: Web-based sub-contractor evaluation system (WEBSES), Automation in Construction 17(4): 480-488. https://doi.org/10.1016/j.autcon.2007.08.004

Ballesteros-Pérez, P.; Skitmore, M.; Pellicer, E.; Zhang, X. 2016. Scoring rules and competitive behavior in best-value con- struction auctions, Journal of Construction Engineering and Management 142(9).

https://doi.org/10.1061/(ASCE)CO.1943-7862.0001144

Bayraktar, M. E.; Cui, Q.; Hastak, M.; Minkarah, I. 2004. Stateof-practice of warranty contracting in the United States, Journal of Infrastructure Systems 10(2): 60-68. https://doi.org/10.1061/(ASCE)1076-0342(2004)10:2(60)

Bereskin, F. L.; Kim, B.; Oh, F. D. 2015. Do credit rating concerns lead to better corporate governance? Evidence from Korea, Pacific-Basin Finance Journal 35, Part B, 592-608.

Biruk, S.; Jaśkowski, P.; Czarnigowska, A. 2017. Modeling contractor's bidding decisions, Procedia Engineering 182: 91-98. https://doi.org/10.1016/j.proeng.2017.03.125

Bottani, E.; Rizzi, A. 2008. An adapted multi-criteria approach to suppliers and products selection - An application oriented to lead-time reduction, International Journal of Production Economics 111: 763-781. https://doi.org/10.1016/j.ijpe.2007.03.012

Chen, Y. S.; Chong, P. P.; Tong, Y. G. 1994. Mathematical and computer modelling of the Pareto principle, Mathematical and Computer Modelling 19(9): 61-80. https://doi.org/10.1016/0895-7177(94)90041-8

Cheng, M. Y.; Hsiang, C. C.; Tsai, H. C.; Do, H. L. 2011. Bidding decision making for construction company using a multicriteria prospect model, Journal of Civil Engineering and Management 17(3): 424-436. https://doi.org/10.3846/13923730.2011.598337

Chotibhongs, R.; Arditi, D. 2012. Analysis of collusive bidding behavior, Construction Management and Economics 30(3): 221-231. https://doi.org/10.1080/01446193.2012.661443

Christodoulou, S. 2010. Bid mark-up selection using artificial neural networks and an entropy metric, Engineering, Construction and Architectural Management 17(4): 424-439. https://doi.org/10.1108/09699981011056600

Drew, D. S.; Skitmore, R. M. 1992. Competitiveness in bidding: a consultant's perspective, Construction Management and Economics 10: 227-247. https://doi.org/10.1080/01446199200000020

Drew, D.; Skitmore, M. 1997. The effect of contract type and size on competitiveness in bidding, Construction Management \& Economics 15(5): 469-489. https://doi.org/10.1080/014461997372836

Egemen, M.; Mohamed, A. N. 2005. Clients' needs, wants and expectations from contractors and approach to the concept of repetitive works in the Northern Cyprus construction market, Building and Environment 41(5): 602-614. https://doi.org/10.1016/j.buildenv.2005.02.021

Fu, W. K.; Drew, D. S.; Lo, H. P. 2003. Competitiveness of inexperienced and experienced contractors in bidding, Journal of Construction Engineering and Management 129(4): 388-395. https://doi.org/10.1061/(ASCE)0733-9364(2003)129:4(388)

Hatush, Z.; Skitmore, M. 1997. Evaluating contractor prequalification data: selection criteria and project success factors, Construction Management and Economics 15(2): 129-147. https://doi.org/10.1080/01446199700000002

Hatush, Z.; Skitmore, M. 1998. Contractor selection using multicriteria utility theory: An additive model, Building and Environment 33(2-3): 105-115. https://doi.org/10.1016/S0360-1323(97)00016-4

Ho, W.; Xu, X.; Dey, P. K. 2010. Multi-criteria decision making approaches for supplier evaluation and selection: A literature review, European Journal of Operational Research 202(1): 1624. https://doi.org/10.1016/j.ejor.2009.05.009 
Holt, G. D.; Olomolaiye, P. O.; Harris, F. C. 1995. A review of contractor selection practice in the U.K. construction industry, Building and Environment 30(4): 553-561. https://doi.org/10.1016/0360-1323(95)00008-T

Hwang, B. G.; Liao, P. C.; Leonard, M. P. 2011. Performance and practice use comparisons: Public vs. Private owner projects, KSCE Journal of Civil Engineering 15(6): 957-963. https://doi.org/10.1007/s12205-011-1115-y

Kassarjian, H. H. 1977. Content analysis in consumer research, Journal of Consumer Research 4: 8-18. https://doi.org/10.1086/208674

Kim, H.-J.; Reinschmidt, K. F. 2011. Effects of contractors' risk attitude on competition in construction, Journal of Construction Engineering and Management 137(4): 275-283. https://doi.org/10.1061/(ASCE)CO.1943-7862.0000284

Kog, F.; Yaman, H. 2014. A meta classification and analysis of contractor selection and prequalification, Procedia Engineering 84: 302-310. https://doi.org/10.1016/j.proeng.2014.10.555

Labuschagne, C.; Brent, A. C. 2005. Sustainable project life cycle management: The need to integrate life cycles in the manufacturing sector, International Journal of Project Management 23(2): 159-168. https://doi.org/10.1016/j.ijproman.2004.06.003

Lambropoulos, S. 2013. Objective construction contract award using cost, time and durability utility, Procedia - Social and Behavioral Sciences 74: 123-133. https://doi.org/10.1016/j.sbspro.2013.03.052

Littlechild, S. 2017. Regulation and the nature of competition, Journal of Air Transport Management 67: 211-223.

Liu, B. S.; Huo, T. F.; Liao, P. C.; Yuan, J. F.; Sun, J.; Hu, X. 2016. A Special Partial Least Squares (PLS) path decision modeling for bid evaluation of large construction projects, KSCE Journal of Civil Engineering, 1-14.

Liu, B. S.; Huo, T. F.; Wang, X. Q.; Shen, Q. P.; Chen, Y. 2013.The decision model of the intuitionistic fuzzy group bid evaluation for urban infrastructure projects considering social costs, Canadian Journal of Civil Engineering 40(3): 263-273.

https://doi.org/10.1139/cjce-2012-0283

Liu, B. S.; Yang, X. D.; Huo, T. F.; Shen, Q. P.; Wang, X. Q. 2017. A linguistic group decision-making framework for bid evaluation inmega public projects considering carbon dioxide emissions reduction, Journal of Cleaner Production 148: 811-825. https://doi.org/10.1016/j.jclepro.2017.02.044

Lu, W. S.; Shen, L. Y.; Yam, M. C. H. 2008. Critical success factors for competitiveness of contractors: China study, Journal of Construction Engineering and Management 134(12): 972-982. https://doi.org/10.1061/(ASCE)0733-9364(2008)134:12(972)

Mesa, H. A.; Molenaar, K. R.; Alarcón, L. F. 2016. Exploring performance of the integrated project delivery process on complex building projects, International Journal of Project Management 34(7): 1089-1101.

https://doi.org/10.1016/j.ijproman.2016.05.007

Newcombe, R. 1990. Construction management 1: Organisation systems. London: Mitchell Publishing Co.

Ng, S. T.; Skitmore, R. M. 1999. Client and consultant perspectives of prequalification criteria, Building and Environment 34(5): 607-621. https://doi.org/10.1016/S0360-1323(98)00050-X

Nieto-Morote, A.; Ruz-Vila, F. 2012. A fuzzy multi-criteria decision-making model for construction contractor prequalification, Automation in Construction 25(18): 8-19. https://doi.org/10.1016/j.autcon.2012.04.004

Oo, B. L.; Drew, D. S.; Lo, H. P. 2008. A comparison of contractors' decision to bid behaviour according to different market environments, International Journal of Project Management 26(4): 439-447.

https://doi.org/10.1016/j.ijproman.2007.06.001

Shash, A. A. 1993. Factors considered in tendering decisions by top UK contractors, Construction Management and Economics 11(2): 111-118. https://doi.org/10.1080/01446199300000004

Smith, A. 1776. The wealth of nations. London: Stratton and Cadell.

Tang, S. L.; Lu, M.; Chan, Y. L. 2003. Achieving client satisfaction for engineering consulting firms, Journal of Management in Engineering 19(4): 166-172. https://doi.org/10.1061/ (ASCE)0742-597X(2003)19:4(166)

Torres, R.; Heyman, R.; Munoz, S.; Apgar, L.; Timm, E.; Tzintzun, C.; Hale, C. R.; Gonzalez, J. M.; Speed, S.; Tang, E. 2013. Building Austin, building justice: Immigrant construction workers, precarious labor regimes and social citizenship, Geoforum 45: 145-155.

https://doi.org/10.1016/j.geoforum.2012.10.012

Watt, D. J.; Kayis, B.; Willey, K. 2009. Identifying key factors in the evaluation of tenders for projects and services, International Journal of Project Management 27(3): 250-260. https://doi.org/10.1016/j.ijproman.2008.03.002

Watt, D. J.; Kayis, B.; Willey, K. 2010. The relative importance of tender evaluation and contractor selection criteria, International Journal of Project Management 28(1): 51-60. https://doi.org/10.1016/j.ijproman.2009.04.003

Wong, C. H.; Holt, G. D.; Cooper, P. A. 2000. Lowest price or value? Investigation of UK construction clients' tender selection process, Construction Management and Economics 18: 767-774. https://doi.org/10.1080/014461900433050

Wong, C. H.; Holt, G. D.; Harris, P. 2001. Multi-criteria selection or lowest price? Investigation of UK construction clients' tender evaluation preferences, Engineering, Construction and Architectural Management 8(4): 105-115.

Wright, R. 2000. Nonzero: the logic of human destiny, Quarterly Review of Biology 5(3).

Wu, I. C.; Borrmann, A.; Beißert, U.; König, M.; Rank, E. 2010. Bridge construction schedule generation with pattern-based construction methods and constraint-based simulation, Advanced Engineering Informatics 24(4): 379-388. https://doi.org/10.1016/j.aei.2010.07.002

Yan, H. Y. 2011. The construction project bid evaluation based on gray relational model, Procedia Engineering 15: 4553-4557. https://doi.org/10.1016/j.proeng.2011.08.855

Yang, J. B.; Wang, H. H.; Wang, W. C.; Ma, S. M. 2016. Using data envelopment analysis to support best-value contractor selection, Journal of Civil Engineering \& Management 22(2): 199-209. https://doi.org/10.3846/13923730.2014.897984

Ye, K. H.; Shen, L. Y.; Xia, B.; Li, B. H. 2014. Key attributes underpinning different markup decision between public and private projects: A China study, International Journal of Project Management 32(3): 461-472. https://doi.org/10.1016/j.ijproman.2013.06.001

Ye, K. H.; Zhu, W. N.; Shan, Y. W.; Li, S. 2015. Effects of market competition on the sustainability performance of the construction industry: China case, Journal of Construction Engineering and Management 141(9), 04015025(1-10).

Zhang, Y.; Luo, H.; He, Y. 2015. A system for tender price evaluation of construction project based on big data, Procedia Engineering 123: 606-614.

https://doi.org/10.1016/j.proeng.2015.10.114 